\title{
Left Ventricular Diastolic Dysfunction as Predictor of Unfavorable Prognosis After ESUS
}

This article was published in the following Dove Press journal:

Journal of Multidisciplinary Healthcare

\author{
Agata Bielecka-Dabrowa $\mathbb{I D}^{1,2}$ \\ Paulina Gasiorek (iD) ${ }^{2}$ \\ Andrzej Wittczak $\mathbb{D I}^{2}$ \\ Agata Sakowicz $\mathbb{1 D}^{3}$ \\ Ibadete Bytyçi $\mathbb{C}^{4,5}$ \\ Maciej Banach $\mathbb{D}^{1,2}$ \\ 'Heart Failure Unit, Department of \\ Cardiology and Congenital Diseases of \\ Adults, Polish Mother's Memorial Hospital \\ Research Institute (PMMHRI), Lodz, \\ Poland; ${ }^{2}$ Department of Hypertension, \\ Chair of Nephrology and Hypertension, \\ Medical University of Lodz, Lodz, Poland; \\ ${ }^{3}$ Department of Medical Biotechnology, \\ Medical University of Lodz, Lodz, Poland; \\ ${ }^{4}$ Clinic of Cardiology, University Clinical \\ Centre of Kosovo, Prishtina, Kosovo; \\ ${ }^{5}$ Institute of Public Health and Clinical \\ Medicine, Umeå University, Umeå, Sweden
}

Correspondence: Agata Bielecka-Dabrowa Heart Failure Unit, Department of Cardiology and Congenital Diseases of Adults, Polish Mother's Memorial Hospital Research Institute (PMMHRI), Rzgowska 28I/289, Lodz, 93-338, Poland

Tel +4842 27II I5 97

Fax +48422711591

Email agatbiel7@poczta.onet.pl
Objective: Identification of echocardiographic, hemodynamic and biochemical predictors of unfavorable prognosis after embolic strokes of undetermined etiology (ESUS) in patients at age $<65$.

Patients and Methods: Out of 520 ischemic stroke patients we selected 64 diagnosed with ESUS and additional 36 without stroke but with similar risk profile. All patients underwent echocardiography, non-invasive assessment of hemodynamic parameters using SphygmoCor tonometer and measurements of selected biomarkers. Follow-up time was 12 months.

Results: Nine percent of patients died, and recurrent ischemic stroke occurred in $9 \%$ of patients only in the ESUS group. Atrial fibrillation (AF) occurred in $10 \%$ of patients and the ESUS group had a significantly poorer outcome of AF in the first 2 months after hospitalization. The outcome of re-hospitalization was $28 \%$ in the ESUS group and $17 \%$ in the control group. In the multivariate analysis mean early diastolic (E') mitral annular velocity (OR 0.75 , 95\% CI: 0.6-0.94; $\mathrm{p}=0.01)$ was significantly associated with cardiovascular hospitalizations. The only independent predictor of recurrent stroke was the ratio of peak velocity of early diastolic transmitral flow to peak velocity of early diastolic mitral annular motion (E/E') (OR 0.75, 95\% CI: 0.6-0.94; p=0.01). E/E' was independently associated with composite endpoint (death, hospitalization and recurrent stroke) (OR 1.90, 95\% CI 1.1-3.2, p=0.01).

Conclusion: The indices of diastolic dysfunction are significantly associated with unfavorable prognosis after ESUS. There is a robust role for outpatient cardiac monitoring especially during the first 2 months after ESUS to detect potential AF.

Keywords: ischemic stroke of undetermined etiology, atrial fibrillation, diastolic heart failure, diastolic dysfunction

\section{Introduction}

Stroke is ranked as the second leading cause of death worldwide and the economic costs of treatment and post-stroke care are substantial. ${ }^{1}$ Ischemic strokes make up over $80 \%$ of all strokes and are the result of obstruction of arteries supplying the brain. $^{2}$

The TOAST (Trial of ORG 10172 in Acute Stroke Treatment) classification of ischemic strokes distinguished 5 groups depending on an etiology: 1) large-artery atherosclerosis; 2) cardioembolism; 3) small-vessel occlusion (lacunar strokes); 4) stroke of other determined etiology and 5) stroke of undetermined etiology. ${ }^{3}$ The term of cryptogenic stroke is commonly used to describe ischemic strokes of undetermined etiology, which in the TOAST classification may refer to a stroke with multiple etiologies, stroke with incomplete diagnostic work-up or when no cause of ischemia is found despite extensive assessment. ${ }^{2,4,5}$ 
In 2014 the Cryptogenic Stroke/ESUS International Working Group introduced the term of embolic stroke of undetermined source (ESUS). The set criteria to define ESUS were formulated, which facilitated the conduction of randomized controlled trials in this population. It was not possible with the original cryptogenic stroke definition. ${ }^{6}$ ESUS can be diagnosed only if stroke is detected by computed tomography (CT) or magnetic resonance imaging (MRI) and is not lacunar (lacunar stroke defined as a subcortical infarct $\leq 1.5 \mathrm{~cm}$ on $\mathrm{CT}$ or $\leq 2 \mathrm{~cm}$ on MRI in largest dimension); there is an absence of extracranial or intracranial atherosclerosis causing $\geq 50 \%$ luminal stenosis in arteries supplying the area of ischemia; no major-risk cardioembolic source of embolism is detected and no other specific cause of stroke is identified (such as arteritis, dissection, migraine/vasospasm, drug misuse). ${ }^{7}$

Cardioembolism accounts for around 15-30\% of ischemic strokes. ${ }^{4}$ This includes major-risk cardiac sources of embolism such as permanent or paroxysmal atrial fibrillation (AF), infective endocarditis and prosthetic cardiac valve. ${ }^{7}$ However, there are cardiac pathologies with a lower risk of embolism, which could be etiologically associated with ESUS. ${ }^{5,6}$

Cardioembolic stroke is associated with a higher risk of recurrent stroke, hospital readmission, severe disability and death compared with other stroke subtypes. ${ }^{4}$ The risk of stroke recurrence in patients with ESUS is nearly 5\% per year and the optimal therapeutic strategy for preventing the recurrence is unclear. ${ }^{8}$

The study is aimed to identify echocardiographic, hemodynamic and biochemical predictors of unfavorable prognosis of ESUS in patients at age $<65$ years.

\section{Patients and Methods}

\section{Study Population}

We prospectively investigated 520 patients with confirmed ischemic stroke hospitalized in the Department of Neurology and Ischemic Strokes. We selected 64 patients diagnosed with ESUS to the first group [median age 54 (IQR 47-58) years, 42\% males]. To the control group we enrolled 36 patients without a history of stroke but with similar risk profile hospitalized in the Department of Hypertension [median age 53 (47-58) years, 61\% males]. All patients underwent transthoracic echocardiography, $72 \mathrm{~h}$ Holter electrocardiogram monitoring and noninvasive assessment of hemodynamic parameters using
SphygmoCor tonometer. ${ }^{9-11}$ Other measurements obtained included the levels of selected biomarkers.

After a one-year follow-up, we collected data on the survival outcomes of all patients, along with data on recurrence of stroke, development of $\mathrm{AF}$, cardio-vascular rehospitalization (due coronary atherosclerosis, heart failure, acute myocardial infarction, stroke and atrial fibrillation) and clinical condition assessment (blood pressure, signs and symptoms of cardiovascular diseases).

The exclusion criteria during enrollment to the study were as follows: hyperthyroidism, AF, cancer, unstable hypertension, pregnancy and breastfeeding, dialysis, autoimmunologic disease, reception of cytotoxic/immunosuppressive/antiretroviral drugs, use of glucocorticosteroids, transplant and treatment with hematogenous preparation during the last 6 months, addiction to medicines, active infection, alcoholism, infection with hepatitis $\mathrm{B}$ virus (HBV)/hepatitis $\mathrm{C}$ virus (HCV)/human immunodeficiency virus (HIV), vaccination during the last 3 months, surgical intervention or serious injury during the last 1 month, and being incapable of giving consent. ${ }^{9,10}$

All enrolled patients underwent blinded adjudication by cardiologists experienced in adjudication. Detailed clinical, biomarker and imaging data were collected at the time of enrollment. Echocardiography and SphygmoCor analysis were performed and interpreted by cardiologists blinded to biomarker analysis. In order to measure central systolic and diastolic pressures we used a sphygmomanometer. A stethoscope was used for peripheral pressure measurement.

All methods in this study were performed in accordance with the guidelines and regulations approved by the Bioethics Commission of the Medical University of Lodz and approval from this commission (No. RNN/272/ 16/KE) was obtained. Written informed consent was obtained from all the patients. The study was registered at ClinicalTrials.gov - identifier number: NCT03377465 (Biomarkers, Hemodynamic and Echocardiographic Predictors of Ischemic Strokes and Their Influence on the Course and Prognosis). The study was conducted in accordance with the Declaration of Helsinki.

\section{Echocardiography}

After enrollment, all patients were examined following a standardized protocol using an ALOKA Alpha 10 Premier (Tokyo, Japan) with a 3-11 $\mathrm{MHz}$ probe. Quantitative echocardiography was used following current guidelines. ${ }^{12}$ Ejection fraction (EF) and left ventricular 
volumes were determined by the biplane Simpson's method. The Devereux formula was used to calculate the left ventricular mass. The early (E) and atrial filling (A) peak velocities, E/A ratio, isovolumic relaxation time and deceleration time of early filling were measured from the transmitral flow. The apical 4-chamber view and pulsed wave tissue Doppler were used to record peak systolic $\left(\mathrm{S}^{\prime}\right)$, early diastolic $\left(E^{\prime}\right)$, and late diastolic $\left(A^{\prime}\right)$ mitral annular myocardial velocities of the left ventricle septal and lateral walls, the results were averaged. The E/E' was calculated as an index of LV filling pressure. ${ }^{12}$

\section{Laboratory Tests}

Blood samples for laboratory tests were collected from all enrolled patients in a hospital setting. The collection of samples was followed by a minimum 12-hour period of fasting. All tests were performed in the hospital laboratory.

Routine laboratory tests were done at the initial time point of the study. $19.5 \mathrm{~mL}$ of blood was collected with a vacuum blood collection system from the basilic vein into $8.5 \mathrm{~mL}, 5 \mathrm{~mL}$, and $4 \mathrm{~mL}$ clot-activator plastic Vacutainer tubes and into $2 \mathrm{~mL}$ Vacutainer tubes containing ethylenediaminetetraacetic acid (EDTA). The blood samples to perform biomarker analysis were taken on the 7th day after stroke. Enzyme linked-immunosorbent assay (ELISA) tests were conducted for the quantitative determination of interleukin 6 (IL-6) (Gen-Probe, France), $\mathrm{N}$-terminal pro-brain natriuretic peptide (NT-proBNP) (Cloud-Clone Corp, China) and asymmetric dimethylarginine (ADMA) (Immunodiagnostik, Bensheim) in human serum.

\section{Holter ECG}

Seventy-two-hour Holter ECG was recorded in a 2-channel, 5-electrode paradigm with a GE SEER Light Ambulatory Recorder and analyzed with the GE Marquette MARS Holter system (GE Medical Systems, Milwaukee, WI 53223 USA).

\section{Non-Invasive Assessment of Hemodynamic Parameters using the SphygmoCor System}

A commercial device (SphygmoCor 9.0; AtCor Medical, Sydney, Australia) was used 7 days after the stroke for a non-invasive assessment of hemodynamic parameters. ${ }^{13}$ The central (ascending aortic) pressure waveform was derived by radial applanation tonometry. The difference between the first and second systolic peaks on the central pressure waveform was used to calculate central augmented pressure (AP). AP as a percentage of the total pressure waveform height was used to calculate the aortic augmentation index (AIx), which is a composite marker of systemic arterial stiffness and left ventricular afterload. We aimed to obtain high-quality waveforms characterized by a pulse height of $>100$, with pulse length and diastolic variation $\leq 5$. Aortic pulse wave velocity (PWV) along with electrocardiogram-gated sequential tonometry at the carotid and radial sites was used to assess central arterial stiffness. We calculated the path length by subtracting the distance between the carotid recording site and sternal notch from the distance between the radial site and the sternal notch. Pulse wave analysis (PWA) was used to obtain AIx and AP value. In order to calculate PWV, we divided the path length by transit time (meters/second). We obtained the average values of the parameters within an 11 s measurement period (9-10 cardiac cycles), the extreme values were excluded beforehand.

\section{Statistical Analysis}

The STATISTICA 13.1 software package (StatSoft, Poland) was used for analysis. Results were considered significant if $p<0.05$. To assess the normality of distribution the Shapiro-Wilk test was used. Data were presented as mean and standard deviation or median and interquartile range (25-75\%), depending on the data scale and distribution. To compare two groups, two-tailed Student's $t$-test for continuous variables with normal distribution and with homogeneity of variance was used.

For data with normal distribution but lacking homogeneity of variance, the Welsh test was conducted. The Mann-Whitney $U$-test was used for non-normally distributed variables. The prediction of the atrial fibrillation occurrence, as well as survival rate within the next 12 months for the ESUS patients and controls, were calculated by the Kaplan-Meier method. Variables significant in univariate analysis were used for the construction of a multivariate logistic regression model; logistic regression was conducted among the patients from ESUS group $(\mathrm{N}=64)$ vs controls $(\mathrm{N}=36)$.

\section{Results}

\section{Basic Characteristics of Patients}

ESUS patients and controls were well matched for baseline characteristics including systolic and diastolic blood pressures, body mass index (BMI), or additional diseases 
such as diabetes, coronary artery disease (CAD) and hypertension. Smoking was more frequent in the ESUS group ( $38 \%$ vs $13 \%$; $=0.02$ ) (Table 1$).{ }^{9-11}$
In echocardiography median value of left ventricular ejection fraction (LVEF) was slightly lower in the ESUS group [60 (55-64) \% vs $63(60-66) \%$; $\mathrm{p}=0.009]$ but the

Table I Basic Characteristics of Patients in Both Groups

\begin{tabular}{|c|c|c|c|}
\hline Parameters & Patients with ESUS $(\mathrm{N}=64)$ & Control Group $(\mathrm{N}=36)$ & $\mathbf{p}$ \\
\hline Gender (male) [\%] & 42 & 61 & 0.059 \\
\hline Median age [years] & $54(47-58) *$ & $53(47-58)^{*}$ & 0.89 \\
\hline BMI $\left[\mathrm{kg} / \mathrm{m}^{2}\right]$ & $26.1(22.4-28.7)^{*}$ & $25(21.8-28.1)^{*}$ & 0.49 \\
\hline $\mathrm{SBP}[\mathrm{mmHg}]$ & $136 \pm 18.7$ & $128 \pm 19.7$ & 0.05 \\
\hline $\mathrm{DBP}[\mathrm{mmHg}]$ & $82 \pm 9.9$ & $81.8 \pm 9$ & 0.72 \\
\hline CAD [\%] & 9 & 9 & 0.76 \\
\hline Hypertension [\%] & 52 & 43 & 0.36 \\
\hline DM [\%] & 8 & 0 & 0.23 \\
\hline Smoking [\%] & 38 & 13 & 0.02 \\
\hline \multicolumn{4}{|l|}{ Laboratory results } \\
\hline LDL cholesterol [mmol/l] & $2.83(2.07-4)^{*}$ & $3.02(2.66-3.67)^{*}$ & 0.37 \\
\hline HDL cholesterol [mmol/l] & $1.19(0.95-1.46)^{*}$ & $1.37(1.19-1.6)^{*}$ & 0.02 \\
\hline Triglycerides [mmol/l] & $1.58(\mathrm{I} . \mathrm{II}-2)^{*}$ & $1.33(0.86-1.7)^{*}$ & 0.16 \\
\hline Adiponectin $[\mu \mathrm{g} / \mathrm{mL}]$ & $6.65(3.99-10.03)$ & $6.62(4.47-8.80)$ & 0.70 \\
\hline \multicolumn{4}{|c|}{ Selected echocardiographic parameters } \\
\hline LVEF [\%] & $60(55-64)^{*}$ & $63(60-66)^{*}$ & 0.009 \\
\hline$E[\mathrm{~cm} / \mathrm{s}]$ & $69 \pm 17$ & $76 \pm 17$ & 0.09 \\
\hline$A[\mathrm{~cm} / \mathrm{s}]$ & $79 \pm 19$ & $64 \pm 17$ & 0.001 \\
\hline Mean E' $[\mathrm{cm} / \mathrm{s}]$ & $8.6(7.1-10.3)^{*}$ & $12.5(9.6-14)^{*}$ & 0.0008 \\
\hline$S^{\prime}[\mathrm{cm} / \mathrm{s}]$ & $7.0 \pm 1.0$ & $8.0 \pm 1.0$ & 0.03 \\
\hline $\mathrm{E} / \mathrm{E}^{\prime}[\mathrm{cm} / \mathrm{s}]$ & $7.6(6.1-8.9)^{*}$ & $6.0(5.3-6.9)^{*}$ & 0.0002 \\
\hline LVMI $\left[\mathrm{g} / \mathrm{m}^{2}\right]$ & $112(90-125.5)^{*}$ & $89.5(77-101)^{*}$ & 0.0004 \\
\hline $\mathrm{LA}[\mathrm{mm}]$ & $36(33-4 I) *$ & $35(32-38) *$ & 0.07 \\
\hline LAVI $\left[\mathrm{mL} / \mathrm{m}^{2}\right]$ & $27 \pm 11$ & $21 \pm 5$ & 0.01 \\
\hline IVRT $[\mathrm{m} / \mathrm{s}]$ & $113 \pm 23$ & $97 \pm 30$ & 0.001 \\
\hline \multicolumn{4}{|c|}{ Evaluation of hemodynamic parameters using SphygmoCor system } \\
\hline AP $[\mathrm{mmHg}]$ & $11.0(7-18)^{*}$ & $6.0(3-13)^{*}$ & 0.0018 \\
\hline Alx [\%] & $27 \pm 13$ & $22 \pm 13$ & 0.03 \\
\hline Alx75 [\%] & $25 \pm 11$ & $18 \pm 12$ & 0.009 \\
\hline $\mathrm{PWV}[\mathrm{m} / \mathrm{s}]$ & $7.2(6.1-8.4)^{*}$ & $7.4(6.2-9.4)^{*}$ & 0.24 \\
\hline HRV index & $6.6(4.7-9)^{*}$ & $8.7(5.9-12.1)^{*}$ & 0.006 \\
\hline DP aortic $[\mathrm{mmHg}]$ & $83.0(78-90)^{*}$ & $81.0(76-90)^{*}$ & 0.59 \\
\hline SP aortic $[\mathrm{mmHg}]$ & $121.28 \pm 17.72$ & $124.64 \pm 18.27$ & 0.42 \\
\hline \multicolumn{4}{|l|}{ Selected biomarkers } \\
\hline ADMA $[\mu \mathrm{mol} / /]$ & $0.44(0.39-0.55)^{*}$ & $0.36(0.32-0.4)^{*}$ & 0.0002 \\
\hline IL-6 [pg/mL] & $2.6(0.8-8.1)^{*}$ & $0.7(0.4-1.2)^{*}$ & 0.002 \\
\hline NT-proBNP [pg/mL] & $391(107.9-1249.22) *$ & $109(46.22-236.9)^{*}$ & 0.0003 \\
\hline
\end{tabular}

Notes: *Median; for parameters with nonnormal distribution median values, lower and higher values are given. For parameters with normal distribution mean values \pm standard deviation (SD) are given.

Abbreviations: BMI, body mass index; SBP, systolic blood pressure; DBP, diastolic blood pressure; CAD, coronary artery disease; DM, diabetes mellitus; LDL, low-density lipoprotein; HDL, high-density lipoprotein; LVEF, left ventricular ejection fraction; E, early diastolic filling velocity; A, late diastolic filling velocity; E', early diastolic mitral annular velocity; S', right ventricular systolic excursion velocity; A', late mitral annular motion; E/E', ratio of peak velocity of early diastolic transmitral flow to peak velocity of early diastolic mitral annular motion; LVMI, left ventricular mass index; LA, left atrium; LAVI, left atrial volume index; IVRT, isovolumetric relaxation time; AP, augmentation pressure; Alx-augmentation index; Alx75, adjusted augmentation index at heart rate 75 beats per minute; PWV, pulse wave velocity; HRV index, heart rate velocity; DP, diastolic pressure; SP, systolic pressure; ADMA, asymmetric dimethylarginine; IL-6, interleukin 6; NT-proBNP, N-terminal prohormone of brain natriuretic peptide. 
function was within the norm in both groups. Compared to controls, patients with ESUS had lower mean early diastolic (E') [8.6 (7.1-10.3) cm/s vs $12.5(9.6-14) \mathrm{cm} / \mathrm{s}$; $\mathrm{p}=0.0008$ ] and systolic (S') [mean $7 \pm 1 \mathrm{~cm} / \mathrm{s}$ vs $8 \pm 1 \mathrm{~cm} /$ $\mathrm{s} ; \mathrm{p}=0.03$ ] mitral annular velocity and a higher ratio of peak velocity of early diastolic transmitral flow to peak velocity of early diastolic mitral annular motion (E/E') [7.6 (6.1-8.9) vs $6.0(5.3-6.9), \mathrm{p}=0.0002]$. The peak velocity flow in late diastole (A wave) value and LV mass indexed to body surface area (LVMI) $\left(\mathrm{g} / \mathrm{m}^{2}\right)$ were higher in ESUS group than in control group $[80 \pm 19 \mathrm{~cm} / \mathrm{s}$ vs 64 $\pm 17 \mathrm{~cm} / \mathrm{s} ; \mathrm{p}=0.01$ and $112(90-125) \mathrm{g} / \mathrm{m}^{2}$ vs $89(77-101)$ $\left.\mathrm{g} / \mathrm{m}^{2} ; \mathrm{p}=0.0004\right]$. Compared to the control group, in the ESUS patients isovolumetric relaxation time (IVRT) was longer [ $113 \pm 23 \mathrm{~ms}$ vs $97 \pm 30 \mathrm{~ms} ; \mathrm{p}=0.001]$ and mean left atrial volume index (LAVI) was higher $[27 \pm 11$ vs $21 \pm 5$; $\mathrm{p}=0.01]$ (Table 1).

Parameters of arterial stiffness such as augmentation pressure (AP), augmentation index (AIx) and augmentation index adjusted to a heart rate of $75 \mathrm{bpm}$ (AIx75) were higher in ESUS group compared to control [11 (7-18) $\mathrm{mmHg}$ vs $6(3-13) \mathrm{mmHg} ; \mathrm{p}=0.001]$ and $[27 \pm 13 \%$ vs 22 $\pm 13 \% ; \mathrm{p}=0.03]$ and $[25 \pm 11$ vs $18 \pm 12 ; \mathrm{p}=0.009]$ respectively (Table 1).

Patients in the ESUS group had higher levels of asymmetric dimethylarginine (ADMA) [0.44 (0.39-0.55) $\mu \mathrm{mol} /$ $\mathrm{L}$ vs $0.36(0.32-0.4) \mu \mathrm{mol} / \mathrm{L} ; \mathrm{p}=0.0002]$, interleukin 6 (IL6) $[2.6(0.8-8.1) \mathrm{pg} / \mathrm{mL}$ vs $0.7(0.4-1.2) \mathrm{pg} / \mathrm{mL} ; \mathrm{p}=0.002]$ and N-terminal pro-brain natriuretic peptide (NT-proBNP) [391 (107-1249) pg/mL vs 109 (46-236) pg/mL; p=0.003] than the control group (Table 1). ${ }^{9-11}$

\section{Follow-Up}

At 12-month follow-up, 6 patients (9\%) from the ESUS group had died and recurrent ischemic stroke also occurred in 6 patients $(9 \%)$ from this group. All patients from the control group survived (Figure 1).

Patients who died had significantly lower levels of LDL $\left[\begin{array}{llllll}2.25 & (1.53-2.77) & \mathrm{mmol} / 1 & \text { vs } & 3.01 & (2.41-3.78)\end{array}\right.$ $\mathrm{mmol} / \mathrm{l} ; \mathrm{p}=0.02)]$ and HDL cholesterol [0.9 (0.84-1.05) $\mathrm{mmol} / \mathrm{l}$ vs $1.3(1.07-1.52) \mathrm{mmol} / \mathrm{l} ; \mathrm{p}=0.01]$ than patients who survived. The level of triglycerides was higher [2.11 (1.81-2.42) $\mathrm{mmol} / \mathrm{l}$ vs $1.39(1.02-1.86) \mathrm{mmol} / \mathrm{l} ; \mathrm{p}=0.02)]$ in patients who died. Patients who died had also lower level of adiponectin [3.3 (3.02-4.7) $\mu \mathrm{g} / \mathrm{mL}$ vs 6.7 (4.3-10.17) $\mu \mathrm{g} / \mathrm{mL}$; $=0.02]$, along with lower value of mean early diastolic (E') mitral annular velocity $[7.95$ $(7.85-8.15) \mathrm{cm} / \mathrm{s}$ vs $9.95(8-13) \mathrm{cm} / \mathrm{s} ; \mathrm{p}=0.04]$ and lower

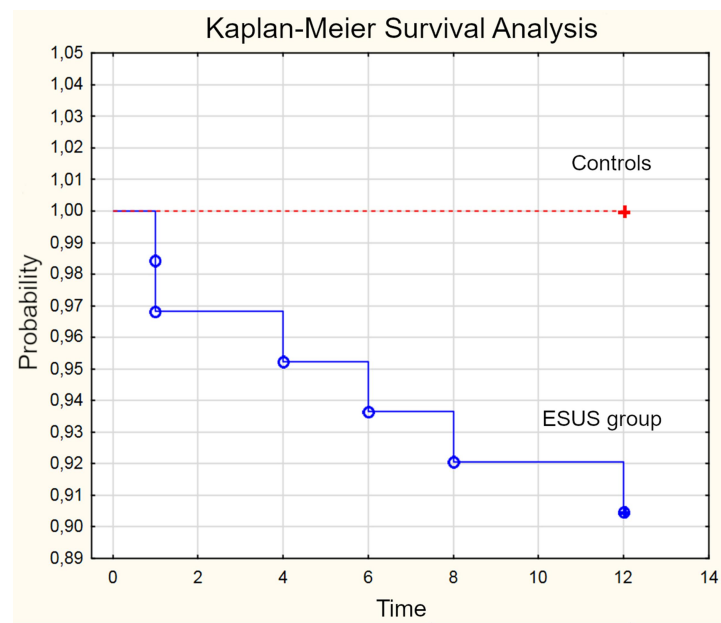

Figure I Kaplan-Meier survival analysis. Abbreviation: ESUS, embolic strokes of undetermined etiology.

diastolic blood pressure (DBP) $[74.83 \pm 10.53 \mathrm{mmHg}$ vs $82.86 \pm 9.4 \mathrm{mmHg} ; \mathrm{p}=0.05$ ] (Table 2).

$\mathrm{AF}$ occurred in $10 \%$ of all patients during the 12 months (log-rang, $\mathrm{p}=0.254$ ) (Figure 2). The Log rank test showed that the ESUS group had a significantly poorer outcome of AF in the first 2 months after hospitalization compared to the reference group ( $11 \%$ vs $5 \%, \mathrm{p}=0.041)$. Based on a Kaplan-Meier analysis, the outcome of rehospitalization in the first year was $28 \%(18 / 64)$ in the ESUS group and $17 \%(6 / 36)$ in the control group (log-rank, $\mathrm{p}=0.058$ ). In patients with $\mathrm{AF}$, the value of tissue Dopplerderived right ventricular systolic excursion velocity (S') was significantly lower than in patients without AF [11 $(10-11.6) \mathrm{cm} / \mathrm{s}$ vs $13.2(11.8-15.6) \mathrm{cm} / \mathrm{s} ; \mathrm{p}=0.015]$.

In the univariate analysis value of lateral and mean early diastolic (E') mitral annular velocity was significantly lower in patients who were rehospitalized [8.7 $(7.05-10.7) \mathrm{cm} / \mathrm{s}$ vs $11(8.8-14) \mathrm{cm} / \mathrm{s} ; \mathrm{p}=0.006$ and 8.3 $(6.75-10.23) \mathrm{cm} / \mathrm{s}$ vs $10.03(8.1-13.25) ; \mathrm{p}=0.016$, respectively]. Tissue Doppler-derived right ventricular systolic excursion velocity ( $\left.\mathrm{S}^{\prime}\right)$ and mean chloride level were significantly lower in patients with an episode of AF [11 $(10-11.6) \mathrm{cm} / \mathrm{s}$ vs $13.2(11.8-15.6) \mathrm{cm} / \mathrm{s} ; \mathrm{p}=0.015$ and $102.01 \pm 2.02 \mathrm{mmol} / 1$ vs $104.38 \pm 3.68 \mathrm{mmol} / \mathrm{l} ; \mathrm{p}=0.049$, respectively]. Septal, lateral and mean E' were significantly lower in patients with recurrent stroke [5.9 $(5.4-6.0) \mathrm{cm} / \mathrm{s}$ vs $8.5(7.55-10.75) \mathrm{cm} / \mathrm{s} ; \mathrm{p}=0.003$ and $7.25(6.7-8.4) \mathrm{cm} / \mathrm{s}$ vs $9.55(7.8-11) \mathrm{cm} / \mathrm{s} ; \mathrm{p}=0.02$ and $6.63(5.85-7.1) \mathrm{cm} / \mathrm{s}$ vs $9.45(7.85-10.75) \mathrm{cm} / \mathrm{s} ; \mathrm{p}=0.005$, respectively]. Furthermore, in patients with recurrent 
Table 2 Characteristics of Patients Who Survived and Those Who Died

\begin{tabular}{|c|c|c|c|}
\hline Parameters & Patients Who Died $(\mathrm{N}=6)$ & Patients Who Survived $(\mathrm{N}=94)$ & $\mathbf{p}$ \\
\hline \multicolumn{4}{|l|}{ Basic parameters } \\
\hline Gender (male) [\%] & $83 \%$ & $49 \%$ & 0.23 \\
\hline Median age [years] & $54.5(48-57)^{*}$ & $54(47-59)^{*}$ & 0.98 \\
\hline BMI $\left[\mathrm{kg} / \mathrm{m}^{2}\right]$ & $27.3(25.8-29.8)^{*}$ & $25.5(21.8-28.6)^{*}$ & 0.14 \\
\hline SBP [mmHg] & $126 \pm 15.22$ & $134 \pm 19.42$ & 0.3 \\
\hline $\mathrm{DBP}[\mathrm{mmHg}]$ & $75 \pm 10.53$ & $83 \pm 9.41$ & 0.047 \\
\hline CAD [\%] & 16.67 & 8.7 & 0.94 \\
\hline Hypertension [\%] & 50 & 48.39 & 0.73 \\
\hline Smoking [\%] & 50 & 28.89 & 0.53 \\
\hline \multicolumn{4}{|l|}{ Laboratory results } \\
\hline LDL cholesterol [mmol/l] & $2.25(1.53-2.77)^{*}$ & $3.0 \mathrm{I}(2.4 \mathrm{I}-3.78)^{*}$ & 0.015 \\
\hline HDL cholesterol [mmol/l] & $0.9(0.84-1.05)^{*}$ & $1.3(1.07-1.52)^{*}$ & 0.014 \\
\hline Triglycerides [mmol/l] & $2.11(1.8 I-2.42)^{*}$ & $1.39(1.02-1.86)^{*}$ & 0.023 \\
\hline Adiponectin $[\mu \mathrm{g} / \mathrm{mL}]$ & $3.3(3.02-4.7)^{*}$ & $6.71(4.31-10.17)^{*}$ & 0.016 \\
\hline \multicolumn{4}{|c|}{ Selected echocardiographic parameters } \\
\hline LVEF [\%] & $55(55-60)^{*}$ & $60(55-65)^{*}$ & 0.21 \\
\hline$E[\mathrm{~cm} / \mathrm{s}]$ & $64.4 \pm 16.13$ & $72.71 \pm 18.05$ & 0.32 \\
\hline $\mathrm{A}[\mathrm{cm} / \mathrm{s}]$ & $78.6 \pm 11.99$ & $74.57 \pm 20.6$ & 0.67 \\
\hline Mean E' $[\mathrm{cm} / \mathrm{s}]$ & $7.95(7.85-8.15)^{*}$ & $9.95(8-13)^{*}$ & 0.04 \\
\hline$S^{\prime}[\mathrm{cm} / \mathrm{s}]$ & $13.6(\mid 1-14)^{*}$ & $13(11-15.6)^{*}$ & 0.7 \\
\hline $\mathrm{E} / \mathrm{E}^{\prime}[\mathrm{cm} / \mathrm{s}]$ & $8.8(6.29-9.57)^{*}$ & $6.89(5.7 \mid-8.2 I)^{*}$ & 0.22 \\
\hline LVMI $\left[\mathrm{g} / \mathrm{m}^{2}\right]$ & $107.5(96.5-115)^{*}$ & $101(82-120)^{*}$ & 0.65 \\
\hline LA [mm] & $36(33-37)^{*}$ & $36(32-39)^{*}$ & 0.88 \\
\hline LAVI $\left[\mathrm{mL} / \mathrm{m}^{2}\right]$ & $19.92 \pm 15.99$ & $25.69 \pm 9.79$ & 0.33 \\
\hline IVRT [m/s] & $107.2 \pm 15.01$ & $101.91 \pm 28.47$ & 0.68 \\
\hline \multicolumn{4}{|l|}{ Selected biomarkers } \\
\hline ADMA $[\mu \mathrm{mol} / \mathrm{l}]$ & $0.48(0.39-0.69)^{*}$ & $0.42(0.35-0.48)^{*}$ & 0.33 \\
\hline $\mathrm{IL}-6[\mathrm{pg} / \mathrm{mL}]$ & $9.94(1.93-104.39)^{*}$ & $2.16(0.63-4.2)^{*}$ & 0.17 \\
\hline NT-proBNP [pg/mL] & $410.76(147.17-1639)^{*}$ & $225.68(71.45-693.99)^{*}$ & 0.31 \\
\hline
\end{tabular}

Notes: *Median; for parameters with nonnormal distribution median values, lower and higher values are given. For parameters with normal distribution mean values \pm standard deviation (SD) are given.

Abbreviations: BMI, body mass index; SBP, systolic blood pressure; DBP, diastolic blood pressure; CAD, coronary artery disease; DM, diabetes mellitus; LDL, low-density lipoprotein; HDL, high-density lipoprotein; LVEF, left ventricular ejection fraction; E, early diastolic filling velocity; A, late diastolic filling velocity; E', early diastolic mitral annular velocity; S', right ventricular systolic excursion velocity; A', late mitral annular motion; E/E', ratio of peak velocity of early diastolic transmitral flow to peak velocity of early diastolic mitral annular motion; LVMI, left ventricular mass index; LA, left atrium; LAVI, left atrial volume index; IVRT, isovolumetric relaxation time; ADMA, asymmetric dimethylarginine; IL-6, interleukin 6; NT-proBNP, N-terminal prohormone of brain natriuretic peptide.

stroke E/E' was significantly higher [9.06 (8.72-9.72) vs 7.41 (6-8.84); $\mathrm{p}=0.03$ ] and left ventricle mass index (LVMI) was significantly lower $\left[82(69-100) \mathrm{g} / \mathrm{m}^{2}\right.$ vs $\left.113.5(92-132) \mathrm{g} / \mathrm{m}^{2} ; \mathrm{p}=0.03\right]$. In patients both rehospitalized and with recurrent stroke lateral $\mathrm{E}^{\prime}$ and LVMI were significantly lower $\left[\begin{array}{llll}7.85 & (6.7-9.3) & \mathrm{cm} / \mathrm{s} & \text { vs } 9.7\end{array}\right.$ $(8-11) \mathrm{cm} / \mathrm{s} ; \mathrm{p}=0.021$ and $100(91-110) \mathrm{g} / \mathrm{m}^{2}$ vs 116 (89-139) $\mathrm{g} / \mathrm{m}^{2} ; \mathrm{p}=0.04$, respectively] and E/E' was significantly higher [8.64 (7.46-9.33) vs 7.19 (5.77-9.97); $\mathrm{p}=0.047]$.
In the multivariate analysis lower value of mean early diastolic (E') mitral annular velocity was significantly associated with cardiovascular hospitalizations assessed at 12-month follow-up [OR 0.76, 95\% CI: 0.61-0.95; $\mathrm{p}=0.02$ ] (Table 3).

The only independent predictor of AF occurrence in the 12-month follow-up was lower value of tissue Doppler-derived right ventricular systolic excursion velocity ( $\mathrm{S}^{\prime}$ ) [OR $\left.0.65,95 \% \mathrm{Cl} 0.46-0.93 ; \mathrm{p}=0.02\right]$ (Table 3). 


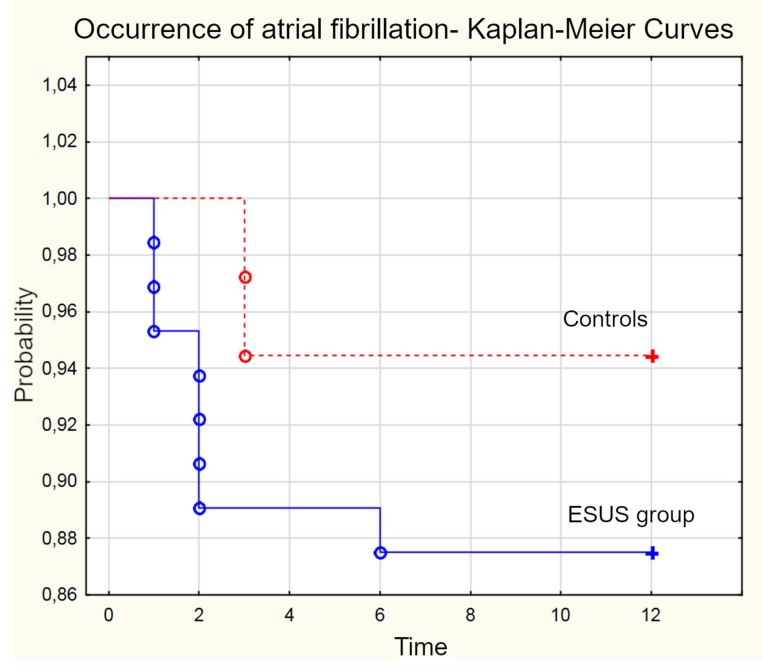

Figure 2 Occurrence of atrial fibrillation - Kaplan-Meier curves. Abbreviation: ESUS, embolic strokes of undetermined etiology.

The only independent predictor of recurrent stroke was higher value of the ratio of peak velocity of early diastolic transmitral flow to peak velocity of early diastolic mitral annular motion as determined by pulsed wave Doppler (E/ E') [OR 7.44, 95\% Cl 1.16-47.6; p=0.03] (Table 3).

Higher $\mathrm{E} / \mathrm{E}$ ' ratio was also independently associated with composite endpoint consisting of hospitalization and recurrent stroke [OR 1.96, 95\% CI 1.18-3.25, $\mathrm{p}=0.01$ ] (Table 3).

\section{Discussion}

\section{Brief Description of Results}

After a one-year follow-up $9 \%$ of patients died (all from ESUS group). They had significantly lower levels of LDL and HDL cholesterol, lower level of adiponectin, lower value of E' and DBP, along with a higher level of triglycerides than patients who survived. ESUS group had a significantly poorer outcome of AF mainly in the first 2 months after hospitalization compared to the reference group. A lower value of E' was significantly associated with cardiovascular hospitalizations and a lower value of $\mathrm{S}$ ' was the predictor of AF occurrence. The higher value of $\mathrm{E} / \mathrm{E}$ ' was the only independent predictor of recurrent stroke and it was also independently associated with composite endpoint consisting of hospitalization and recurrent stroke.

\section{ESUS Recurrence and Fatality Rate}

ESUS recurrence and fatality were the elements of several studies. ${ }^{14-16}$ Hart et al did a systematic literature review to assess the frequency of ESUS, patient features and prognosis. The authors found that the rate of stroke recurrence averaged about $4.5 \%$ per year during a mean follow-up of 2.7 years. The fatality rate was not analyzed. ${ }^{14}$

In the two large trials of oral anticoagulation in ESUS over 12,000 patients were enrolled. In the NAVIGATE ESUS authors compared the efficacy and safety of rivaroxaban (daily dose $15 \mathrm{mg}$ ) with aspirin (daily dose $100 \mathrm{mg}$ ). A total of 7213 participants were enrolled, recurrent ischemic stroke occurred in $4.7 \%$ of patients receiving rivaroxaban and also in $4.7 \%$ of patients receiving aspirin (annualized rates). Death from any cause happened in $1.9 \%$ of patients from the rivaroxaban group and $1.5 \%$ of patients in the aspirin group. ${ }^{15}$ In the RE-SPECT ESUS study authors similarly compared the efficacy and safety of dabigatran (150 mg or $110 \mathrm{mg}$ twice daily) with aspirin

Table 3 Multivariate Analysis

\begin{tabular}{|c|c|c|c|}
\hline Parameters & Odds Ratio (OR) & 95\% Confidence Interval & $\mathbf{p}$ \\
\hline \multicolumn{4}{|c|}{ Cardiovascular hospitalizations assessed at I 2-month follow-up } \\
\hline E' & 0.76 & $0.61-0.95$ & 0.02 \\
\hline \multicolumn{4}{|c|}{ AF occurrence in the 12-month follow-up } \\
\hline S & 0.65 & $0.46-0.93$ & 0.02 \\
\hline \multicolumn{4}{|c|}{ Recurrent stroke at I2-month follow-up } \\
\hline $\mathrm{E} / \mathrm{E}^{\prime}$ & 7.44 & $1.16-47.6$ & 0.03 \\
\hline \multicolumn{4}{|c|}{ Composite endpoint consisting of hospitalization and recurrent stroke at I2-month follow-up } \\
\hline $\mathrm{E} / \mathrm{E}$ & 1.96 & $1.18-3.25$ & 0.01 \\
\hline
\end{tabular}

Abbreviations: E', early diastolic mitral annular velocity; S', right ventricular systolic excursion velocity; E/E', ratio of peak velocity of early diastolic transmitral flow to peak velocity of early diastolic mitral annular motion. 
(daily dose $100 \mathrm{mg}$ ). A total of 5390 patients were enrolled, recurrent strokes occurred in $6.6 \%$ of patients in the dabigatran group and in $7.7 \%$ of patients in the aspirin group. Death from any cause happened in $1.2 \%$ and $1.3 \%$ of patients respectively. ${ }^{16}$

In our study at 12-month follow-up, recurrent ischemic stroke occurred in $9 \%$ of patients from the ESUS group and also $9 \%$ of patients from the ESUS group had died.

\section{Factors Associated with Mortality in ESUS Patients}

Several factors were associated with mortality in our study. Patients who died had significantly lower levels of HDL cholesterol. The inverse association between plasma HDL and the risk of atherosclerotic cardiovascular disease is well-established. ${ }^{17,18}$

Adiponectin is a protein secreted by adipose cells, which increases insulin sensitivity and possesses antiatherogenic properties. Adiponectin receptors are also expressed in the brain. ${ }^{19}$ Low levels of adiponectin were found to be associated with increased mortality after ischemic stroke. ${ }^{19,20}$ In our study, patients who died had significantly lower levels of adiponectin.

We observed significantly lower values of $E^{\prime}$ in patients who died. This suggests that the incidence of left ventricular diastolic dysfunction (LVDD) was higher in these patients. The association between LVDD and ESUS is described in an appropriate section.

There is some evidence that low DBP could be associated with cardiovascular risk. The 2018 ESC/ESH Guidelines for the management of arterial hypertension recommends that the first objective of treatment should be to lower BP to $<140 / 90 \mathrm{mmHg}$ in all patients and a DBP target of $<80 \mathrm{mmHg}$ should be considered for all hypertensive patients. ${ }^{21}$ However, according to the guidelines of the Polish Society of Hypertension, in the treatment of isolated systolic hypertension, the lowering of SBP should not result in lowering DBP below 65 mmHg. ${ }^{22}$ Chen et al demonstrated that, compared with the medium level of DBP (70-80 $\mathrm{mmHg})$, low DBP $(<60 \mathrm{mmHg})$ was associated with a significantly higher risk of composite events (defined as the combination of nonfatal myocardial infarction, nonfatal congestive heart failure, and death of any cause), especially among the elderly. However, the study failed to find an analogical trend for stroke recurrence. ${ }^{23}$ In our study, patients who died had significantly lower DBP than patients who survived.

\section{$\mathrm{AF}$ and ESUS}

Covert AF is considered as one of the most important underlying mechanism in ESUS. AF may be detected in $30 \%$ of ESUS patients during long-term follow-up. ${ }^{6}$ Detection of AF is crucial because the presence of subclinical AF has significant clinical consequences, primarily regarding the use of oral anticoagulation. 2018 American Heart Association/American Stroke Association guidelines for the early management of patients with acute ischemic stroke (along with the 2019 update) recommend that electrocardiographic monitoring should be performed in all patients with ischemic stroke for at least the first 24 hours. $^{24}$ The 2016 Atrial Fibrillation guidelines of the European Society of Cardiology recommends at least 72 $\mathrm{h}$ of Holter ECG monitoring in patients with TIA or ischemic stroke (class IB). ${ }^{25}$

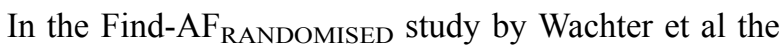
authors compared prolonged ECG-monitoring with standard-care procedures in patients with acute ischemic stroke without a history of AF. The study showed that prolonged examination resulted in a higher detection rate of AF. Most of the AF cases (67\%) were detected within the first 10 days, therefore authors proposed that the Holter-ECG monitoring should be performed for the first 7-10 days after stroke symptoms onset. ${ }^{26}$ Campal et al conducted a prospective study in which authors tried to determine the prevalence of subclinical AF in patients with ESUS. The study showed that an early and prolonged strategy of monitoring (21-day Holter ECG) is more effective in detecting subclinical AF in patients with ESUS, as compared with a strategy calling for a shorter monitoring period or a delayed initiation. ${ }^{27}$

In our study, all patients underwent a $72 \mathrm{~h}$ Holter ECG during the first hospitalization after stroke. AF occurred in $10 \%$ of all patients during one-year follow-up according to assessment of ECGs and patients' medical documentation, including results of ECG monitoring from this time. ESUS group had a significantly poorer outcome of AF in the first 2 months after hospitalization. These results suggest that Holter ECG monitoring in the early months after stroke is particularly significant.

\section{Indices of Diastolic Dysfunction and ESUS}

The association between systolic left ventricular dysfunction and ESUS is well-established and mainly mediated by 
thrombogenesis arising from the co-occurrence of dilated chambers, low cardiac output, poor contractility, endothelial dysfunction and other factors. ${ }^{4}$ Left ventricular diastolic dysfunction is frequent in patients with $\mathrm{AF}$ and is associated with symptom severity and progression of this condition. ${ }^{28}$ It is also associated with a left atrial enlargement, which results in a higher risk of cardioembolism, arrhythmia and atrial thrombogenicity. ${ }^{29}$

It is still not confirmed if there is any association between diastolic dysfunction and the occurrence of cryptogenic stroke/ESUS and what echocardiographic markers of this dysfunction are the most valuable in assessment of patients with the risk of stroke. Seo et al revealed that ventricular diastolic dysfunction in grade II $\left(\mathrm{E}^{\prime}<10 \mathrm{~cm} / \mathrm{s}\right.$, E/e' ratio 9 to 12 , and deceleration time, DT, 160 to 200 $\mathrm{ms})$ and grade III $\left(\mathrm{E}^{\prime}<10 \mathrm{~cm} / \mathrm{s}, \mathrm{E} / \mathrm{e}^{\prime}\right.$ ratio is $>12$, or DT $<160 \mathrm{~ms}$ ) as well as left atrium enlargement $>44 \mathrm{~mm}$ were significantly associated with stroke with AF [odds ratio (OR) 4.37, 95\% confidence interval (CI), 2.99-6.41 and OR 5.60; 95\% CI, 3.42-9.17, and OR 5.19, 95\% CI $3.67-7.35$, respectively)]. The authors found similar frequency of severe LV diastolic dysfunction in patients with cryptogenic stroke and stroke with AF but different from that in stroke without AF what may suggest that more cryptogenic strokes might result from undetected $\mathrm{AF}^{30}$ In our study the parameter of diastolic LV dysfunction E/E' was independently associated with stroke recurrence.

The ratio of peak velocity of early diastolic transmitral flow to peak velocity of early diastolic mitral annular motion (E/E' ratio) is one of the most important echocardiographic parameters in assessing the left ventricle diastolic function. Ryu et al retrospectively analyzed data of 503 patients with acute ischemic stroke and normal LVEF ( $\geq 50 \%$ ). The study showed that a higher value of E/E' was independently related with a higher modified Rankin Scale (mRS) score at 3 months and mortality after ischemic stroke. ${ }^{31}$ In our study lower value of $\mathrm{E}^{\prime}$ (one of indices of LV diastolic dysfunction) was significantly associated with outcomes as cardiovascular hospitalizations assessed at 12-month follow-up.

Arai et al investigated whether $\mathrm{E} / \mathrm{E}$ ' is associated with the incidence of ischemic stroke or new appearance of $\mathrm{AF}$ in patients without AF in 11,477 patients from the Shinken database. Authors found that higher E/E' ratio was independently associated with ischemic events and with the new appearance of AF when adjusting for various cardiovascular risk factors. ${ }^{32}$
There are no studies in which the prognostic value of E/E' ratio was analyzed in the ESUS patients. Our analysis of ESUS group showed that the higher value of E/E' was the independent predictor of recurrent stroke and it was also independently associated with composite endpoint consisting of hospitalization and recurrent stroke. This would suggest that the indices of diastolic dysfunction play an important role in ESUS outcome prognostication.

\section{Limitations of the Study}

The study involved a relatively small number of patients and the findings need to be confirmed in a larger population. Not all patients underwent transesophageal echocardiography (TEE).

\section{Conclusions}

The indices of diastolic dysfunction are significantly associated with unfavorable prognosis after ESUS. There is a robust role for outpatient cardiac monitoring especially during the first 2 months after ESUS to detect potential AF. Our results suggest that in the prevention of ischemic stroke, intensive monitoring of the heart rhythm may be important, especially in patients with indices of diastolic heart failure.

\section{Data Sharing Statement}

Individual participant data that underlie the results reported in this article after deidentification (text, tables and figures) as well as study protocol will be available for researchers who provide a methodologically sound proposal. Proposals may be submitted to the corresponding author after 9 months and up to 36 months following article publication.

\section{Acknowledgment}

The abstract of this paper was presented at the ESC Congress 2019 as a poster presentation with interim findings. The poster's abstract was published in "Poster Abstracts" in the European Heart Journal: https://doi.org/ $\underline{10.1093 / \text { eurheartj/ehz748.0877. }}$

\section{Funding}

The study was financed by research grant no. 502-03/ 5-139-02/502-54-203 and 502-03/5-139-02/502-54-22918 of the Medical University of Lodz, Poland. The ClinicalTrials.gov identifier is NCT03377465. The publication is financed by the Polish National Agency for 
Academic Exchange under the Foreign Promotion Programme.

\section{Disclosure}

The authors declare that they have no conflict of interest.

\section{References}

1. Donkor ES. Stroke in the 21st century: a snapshot of the burden, epidemiology, and quality of life. Stroke Res Treat. 2018;3238165. doi: $10.1155 / 2018 / 3238165$

2. Grysiewicz RA, Thomas K, Pandey DK. Epidemiology of ischemic and hemorrhagic stroke: incidence, prevalence, mortality, and risk factors. Neurol Clin. 2008;26(4):871-vii. doi:10.1016/j. ncl.2008.07.003

3. Chung JW, Park SH, Kim N, et al. Trial of ORG 10172 in Acute Stroke Treatment (TOAST) classification and vascular territory of ischemic stroke lesions diagnosed by diffusion-weighted imaging. $J$ Am Heart Assoc. 2014;3(4):e001119. doi:10.1161/ JAHA.114.001119

4. Gąsiorek PE, Banach M, Maciejewski M, et al. Stroke as a result of cardioembolism - characteristic features in the context of diagnostic methods and secondary prevention. Folia Cardiol. 2018.

5. Gąsiorek PE, Banach M, Maciejewski M, et al. Established and potential echocardiographic markers of embolism and their therapeutic implications in patients with ischemic stroke. Cardiol J. 2019;26 (5):438-450. PMID: 29718528. doi:10.5603/CJ.a2018.0046.

6. Ntaios G. Embolic stroke of undetermined source: JACC review topic of the week. J Am Coll Cardiol. 2020;75(3):333-340. doi:10.1016/j.jacc.2019.11.024

7. Hart RG, Diener HC, Coutts SB, et al.; Cryptogenic Stroke/ESUS International Working Group. Embolic strokes of undetermined source: the case for a new clinical construct. Lancet Neurol. 2014;13(4):429-438. doi:10.1016/S1474-4422(13)70310-7.

8. Geisler T, Mengel A, Ziemann U, Poli S. Management of embolic stroke of undetermined source (ESUS). Drugs. 2018;78(8):823-831. doi:10.1007/s40265-018-0912-8

9. Gąsiorek P, Banach M, Sakowicz A, et al. The potential role of inflammation in cryptogenic stroke. Adv Med Sci. 2019;64 (2):381-387. doi:10.1016/j.advms.2019.06.001

10. Gąsiorek P, Sakowicz A, Banach M, von Haehling S, BieleckaDabrowa A. Arterial stiffness and indices of left ventricular diastolic dysfunction in patients with embolic stroke of undetermined etiology. Dis Markers. 2019;2019:9636197. PMID: 31612072; PMCID: PMC6757252. doi: 10.1155/2019/9636197.

11. Bielecka-Dabrowa A, Gasiorek P, Sakowicz A, Banach M. The cardiovascular predictors of clinical outcomes in patients after ischemic stroke of undetermined etiology. Eur Heart J. 2019;40 (Supplement):1511. doi:10.1093/eurheartj/ehz748.0877

12. Saric M, Armour AC, Arnaout MS, et al. Guidelines for the use of echocardiography in the evaluation of a cardiac source of embolism. $J$ Am Soc Echocardiography. 2016;29(1):1-42.

13. Holland DJ, Sacre JW, Leano RL, Marwick TH, Sharman JE. Contribution of abnormal central blood pressure to left ventricular filling pressure during exercise in patients with heart failure and preserved ejection fraction. J Hypertens. 2011;29(7):1422-1430. doi:10.1097/HJH.0b013e3283480ddc

14. Hart RG, Catanese L, Perera KS, Ntaios G, Connolly SJ. Embolic stroke of undetermined source: a systematic review and clinical update. Stroke. 2017;48(4):867-872. doi:10.1161/ STROKEAHA.116.016414

15. Hart RG, Sharma M, Mundl H, et al. Rivaroxaban for stroke prevention after embolic stroke of undetermined source. $N$ Engl J Med. 2018;378:2191-2201. doi:10.1056/NEJMoa1802686
16. Diener HC, Sacco RL, Easton JD, et al. Dabigatran for prevention of stroke after embolic stroke of undetermined source. $N$ Engl J Med. 2019;380:1906-1917. doi:10.1056/NEJMoa1813959

17. Authors/Task Force Members, ESC Committee for Practice Guidelines (CPG), \& ESC National Cardiac Societies. 2019 ESC/ EAS guidelines for the management of dyslipidaemias: lipid modification to reduce cardiovascular risk. Atherosclerosis. 2019;290:140-205. doi:10.1016/j.atherosclerosis.2019.08.014

18. Bardagjy AS, Steinberg FM. Relationship between HDL functional characteristics and cardiovascular health and potential impact of dietary patterns: a narrative review. Nutrients. 2019;11(6):1231. doi:10.3390/nu11061231

19. Ilhan N, Susam S, Canpolat O, Belhan O. The emerging role of leptin, adiponectin and visfatin in ischemic/hemorrhagic stroke. $\mathrm{Br}$ $J \quad$ Neurosurg. 2019;33(5):504-507. doi:10.1080/ 02688697.2019 .1578862

20. Sasaki M, Otani T, Kawakami M, Ishikawa SE. Elevation of plasma retinol-binding protein 4 and reduction of plasma adiponectin in subjects with cerebral infarction. Metabolism. 2010;59(4):527-532. doi:10.1016/j.metabol.2009.08.015

21. Williams B, Mancia G, Spiering W, et al. 2018 ESC/ESH Guidelines for the management of arterial hypertension. [Eur Heart J. 2019 Feb 1;40(5):475]. Eur Heart J. 2018;39(33):3021-3104. doi:10.1093/eurheartj/ehy339

22. Tykarski A, Filipiak JK, Januszewicz A, et al. Zasady postępowania w nadciśnieniu tętniczym — 2019 rok. Nadcisnienie Tetnicze w Praktyce. 2019;5(1):1-86.

23. Chen Z, Mo J, Xu J, et al. Effect of low diastolic blood pressure to cardiovascular risk in patients with ischemic stroke or transient ischemic attacks under different systolic blood pressure levels. Front Neurol. 2020;11:356. doi:10.3389/fneur.2020.00356

24. Powers WJ, Rabinstein AA, Ackerson T, et al. Guidelines for the Early Management of Patients With Acute Ischemic Stroke: 2019 Update to the 2018 Guidelines for the Early Management of Acute Ischemic Stroke: a Guideline for Healthcare Professionals From the American Heart Association/American Stroke Association. Stroke. 2019;50:e344-e418. doi:10.1161/STR.00000 00000000211

25. Kirchhof P, Benussi S, Kotecha D, et al. 2016 ESC Guidelines for the management of atrial fibrillation developed in collaboration with EACTS: the Task Force for the management of atrial $\mathrm{fi}$ brillation of the European Society of Cardiology (ESC) Developed with the special contribution of the European Heart Rhythm Association (EHRA) of the ESCEndorsed by the European Stroke Organisation (ESO). Eur Heart $J$. 2016;37:2893-2962. doi:10.1093/eurheartj/ehw210

26. Wachter R, Gröschel K, Gelbrich G, et al. Holter-electrocardiogrammonitoring in patients with acute ischaemic stroke (Find-AFRANDOMISED): an open-label randomised controlled trial. Lancet Neurol. 2017;16(4):282-290. doi:10.1016/S14744422(17)30002-9

27. Campal JM, Torres MA, Borque PS, et al. Detecting atrial fibrillation in patients with an embolic stroke of undetermined source (from the DAF-ESUS registry). Am $J$ Cardiol. 2020;125(3):409-414. doi:10.1016/j.amjcard.2019.10.050

28. Kosiuk J, Van Belle Y, Bode K, et al. Left ventricular diastolic dysfunction in atrial fibrillation: predictors and relation with symptom severity. J Cardiovasc Electrophysiol. 2012;23:1073-1077. doi:10.1111/j.1540-8167.2012.02368.x

29. Rosenberg MA, Manning WJ. Diastolic dysfunction and risk of atrial fibrillation: a mechanistic appraisal. Circulation. 2012;126:2353-2362. doi:10.1161/CIRCULATIONAHA.112.113233

30. Seo JY, Lee KB, Lee JG, et al. Implication of left ventricular diastolic dysfunction in cryptogenic ischemic stroke. Stroke. 2014;45:2757-2761. doi:10.1161/STROKEAHA.114.006108 
31. Ryu W-S, Park J-B, Ko S-B, et al. Diastolic dysfunction and outcome in acute ischemic stroke. Cerebrovasc Dis. 2016;41:148-155. doi:10.1159/000442006
32. Arai R, Suzuki S, Semba H, et al. The predictive role of E/e' on ischemic stroke and atrial fibrillation in Japanese patients without atrial fibrillation. J Cardiol. 2018;72(1):33-41. doi:10.1016/j.jjcc.2018.01.001

\section{Publish your work in this journal}

The Journal of Multidisciplinary Healthcare is an international, peerreviewed open-access journal that aims to represent and publish research in healthcare areas delivered by practitioners of different disciplines. This includes studies and reviews conducted by multidisciplinary teams as well as research which evaluates the results or conduct of such teams or healthcare processes in general. The journal covers a very wide range of areas and welcomes submissions from practitioners at all levels, from all over the world. The manuscript management system is completely online and includes a very quick and fair peer-review system. Visit http://www.dovepress.com/testimonials. php to read real quotes from published authors. 